\title{
REFLEXÕES SOBRE A ESCOLA DO CAMPO EM TEMPO INTEGRAL NO MUNICÍPIO DE SANTARÉM - PARÁ
}

\author{
REFLECTIONS ON THE FULL-TIME EDUCATION IN RURAL \\ SCHOOLS OF SANTARÉM, PARÁ, BRAZIL
}

\section{REFLEXIONES SOBRE LA ESCUELA DEL CAMPO A TIEMPO COMPLETO EN EL MUNICIPIO DE SANTARÉM - PARÁ}

\begin{abstract}
Clênya Ruth Alves Vasconcelos ${ }^{\mathrm{I}}$
Solange Helena Ximenes Rocha ${ }^{\mathrm{II}}$
\end{abstract}

'Universidade Federal do Oeste do Pará, Pará - Brasil. E-mail: ruthclenya@gmail.com

IIUniversidade Federal do Oeste do Pará, Pará - Brasil. E-mail: solange.ximenes@gmail.com

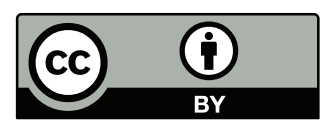

Educação: Teoria e Prática, Rio Claro, SP, Brasil - eISSN: 1981-8106

Está licenciada sob Licença Creative Common

\section{Resumo}

Este texto visa compreender como a política de educação em tempo integral foi implementada em cinco escolas do campo em Santarém (Pará) e de que forma esta tem influenciado no rendimento escolar dos alunos. A pesquisa é caracterizada por ter natureza qualitativa, seguida de pesquisa de campo. Quanto aos sujeitos, foram entrevistados cinco grupos de indivíduos (professores, monitores, pais, diretores e coordenadora Mais Educação). Os instrumentos de coleta de dados partiram da aplicação de entrevistas semiestruturadas, que foram organizadas em categorias e 
interpretadas através da técnica de análise de conteúdo. O estudo reflete sobre a implementação da política de educação integral no município por meio do Programa Mais Educação - (PME). Os resultados preliminares indicam que o programa representa uma ocupação para os alunos, no sentido de tirá-los da ociosidade, além de propiciar melhoras no rendimento acadêmico após participarem do programa. Também indicam que persistem problemáticas na relação entre professores e voluntários do programa, na relação espaço-tempo, bem como na conexão entre as atividades pedagógicas do tempo escolar e do tempo ampliado. O texto analisa essas questões e aponta os desafios da implementação da política de educação em tempo integral nas escolas do campo.

Palavras-chave: Política. Educação de Tempo Integral. Educação no Campo.

\section{Abstract}

This article aims to understand how full-time education policy was implemented at five rural schools in Santarém, Pará, Brazil, and how it has influenced students' school performance. This is a qualitative research, followed by field research. Five groups of individuals (teachers, monitors, parents, directors and education coordinator) were interviewed. Data collection was carried out through application of semi-structure interviews, which were organized in categories and interpreted through content analysis technique. The study reflects on the implementation of full-time education policy in the city through the Mais Educação Program (PME). The preliminary results show that the program represents an occupation for students so as to they get rid of idleness, and there was better academic productivity after their participation in the program. They still indicate difficulties concerning the relationship between teachers and volunteers of the program, in the relation space vs. time, as well as in the connection between pedagogical activities of school period and expanded period. The article analyzes these problems and points out challenges for consolidating the full-time education policy in rural schools.

Keywords: Policy. Full-Time Education. Rural Education.

\section{Resumen}

El texto pretende comprender cómo la politica de educación a tiempo completo fue implementada en cinco escuelas del campo en Santarém, Pará, y de qué forma ha influenciado 
en el rendimiento escolar de los alumnos. La investigación se caracteriza como de naturaleza cualitativa, seguida de investigación de campo, en cuanto a los sujetos, fueron entrevistados cinco grupos de individuos (profesores, monitores, padres, directores y coordinadora Mais Educação). Los instrumentos de recolección de datos comenzaron con la aplicación de entrevistas semiestructuradas, que se organizaron en categorías y fueron interpretadas a través de la técnica de análisis de contenido. El estudio aborda la implementación de la política de educación integral en el Municipio, por el Programa Mais Educação (PME). Los resultados preliminares indican que el programa representa una ocupación para los alumnos, en el sentido de quitarlos de la ociosidad, además de un aumento de rendimiento académico después de participar del programa. Se indica que persisten problemáticas en la relación entre profesores $y$ voluntarios del programa en cuanto a espacio-tiempo, así como en la conexión entre las actividades pedagógicas del tiempo escolar y el tiempo ampliado. El texto analiza estas problemáticas y señala los desafios de la implementación de la política de educación en tiempo completo en las escuelas del campo.

Palabras clave: Politica. Educación en Tiempo Completo. Educación en el Campo.

\section{INTRODUÇÃO}

A política de educação em tempo integral se insere no âmbito das políticas educacionais, figurando como estratégia política e econômica de ampliação do tempo de instrução e melhoria da educação e dos índices de desempenho (standard) com base no desenvolvimento integral dos indivíduos. Em 2012, o campo, como espaço geográfico e político, passou a integrar a política de educação em tempo integral, por meio da criação do Mais Educação Campo constante entre as ações do Programa Nacional de Educação do Campo (Pronacampo). Em sintonia com essa ação, o novo Plano Nacional de Educação (2014-2024) passou a contemplar o campo como espaço de oferta de educação em tempo integral.

Em virtude disso, e entendendo que a implantação do Programa Mais Educação nas escolas deve contribuir para dinamizar a organização pedagógica das escolas do campo, este estudo buscou, como objetivo geral, compreender as experiências pedagógicas da implementação da política de educação em tempo integral nas escolas do campo, do município de Santarém, com os seguintes objetivos específicos: analisar a conexão entre as atividades pedagógicas do tempo escolar e as propostas no tempo ampliado; entender a relação espaço- 
tempo na organização das atividades pedagógicas; e analisar a relação entre a ampliação da jornada escolar e o desempenho acadêmico dos estudantes.

Para tanto, partiremos da discussão sobre educação integral, com base nos escritos de Moll (2012), Cavaliere (2010), documentos de orientação da política como os cadernos pedagógicos da série Mais Educação (BRASIL, 2009) e o Manual Operacional da Educação Integral (BRASIL, 2014).

Em relação ao locus da pesquisa selecionamos cinco escolas do campo do município de Santarém, estado do Pará. Quanto aos sujeitos da pesquisa, foram entrevistados cinco grupos de indivíduos, sendo oito professores, oito monitores, dez pais, quatro diretores, e a coordenadora do Programa Mais Educação, totalizando trinta e um participantes. Assumimos a abordagem qualitativa amparada na pesquisa documental e na pesquisa de campo através da aplicação de entrevistas semiestruturadas, realizadas no período de janeiro a fevereiro de 2017. Para a análise, apoiamo-nos nas técnicas de análise de conteúdo de Bardin (2011). Levando-se em consideração as orientações da técnica de análise de conteúdo, procedeu-se de acordo com a fase chamada por Bardin (2011) de pré-análise do material, que envolveu a organização da literatura sobre as temáticas envolvidas, relatórios produzidos pela secretaria de educação e entrevistas realizadas. Inicialmente, realizou-se a leitura flutuante, de modo a ler exaustivamente o material, na intenção de conhecer os textos. Na sequência, formularam-se as primeiras hipóteses e categorias de análise por meio dos indicadores oriundos das leituras das entrevistas.

\section{POLÍTICA EDUCACIONAL BRASILEIRA E EDUCAÇÃO EM TEMPO INTEGRAL: PERSPECTIVAS E APROXIMAÇÕES COM A EDUCAÇÃO DO CAMPO}

Anísio Teixeira, o principal expoente da concepção de educação integral no Brasil, destacou-se pelas ideias que apresentava sobre a educação e o papel da escola, ideias influenciadas pela aproximação com as obras de John Dewey e Kilpatrick, entre os anos de 1927 a 1928, na Universidade de Columbia nos Estados Unidos, as quais lhes deram bases teóricas e filosóficas para o projeto de reforma da educação no Brasil, que já havia iniciado na Bahia em 1925. Anísio Teixeira identificava-se com as correntes liberais e defendia o caráter público da educação para toda a população, através da criação de uma nova escola democrática e via, na educação integral, a possibilidade de efetivar esse processo. 
Em 1932, foi publicado no Brasil o documento intitulado o Manifesto dos Pioneiros da Educação Nova: ao povo e ao governo. Esse manifesto, de caráter político - social, apontava as necessidades de uma educação nova e, consequentemente, uma escola nova para a sociedade da época; neste, a concepção de educação integral era evidenciada e propunha-se uma educação pública assentada em uma formação ampla que abrangesse as diferentes dimensões da formação humana.

Na base das propostas de educação, de Anísio Teixeira, estava a crítica à escola com papel simplista. Ganhou força nas discussões em âmbito político a necessidade da implementação da educação integral a partir da ampliação do tempo, com a visão político - estratégica de construção de uma sociedade mais democrática, através da oferta da educação. Nos anos de 1980 e 1990 houve o ressurgimento da essência das propostas de Anísio Teixeira através da criação do Programa dos Centros Integrados de Educação Pública do Rio de Janeiro (CIEPs) (CAVALIERE, 2010). A Educação, na perspectiva de jornada ampliada, retorna assim na década de 1990, inspirada na Lei de Diretrizes e Bases da Educação (Lei no 9.394, de 20 de dezembro de 1996), a qual previu no Art. 34, a educação integral (BRASIL, 1996). A partir dessa conjuntura, a educação em tempo integral passou a ser reconhecida e legitimada na agenda da política educacional brasileira. No ano de 2001, com a aprovação da Lei n ${ }^{\circ} 10.172$, de 9 de janeiro de 2001, foi elaborado o Plano Nacional de Educação (PNE), contemplando a Educação Integral de forma mais focalizada do que na LDB, de 1996.

Para Moll (2012, p. 27), “o divisor de águas” para a educação em tempo integral se consolidar como política veio com o financiamento da educação de tempo integral pelo Fundo de Manutenção e Desenvolvimento da Educação Básica e de Valorização dos Profissionais da Educação (FUNDEB), instituído pela Lei no 11.494, de 20 de junho de 2007 (BRASIL, 2007), a qual "contemplou o financiamento da educação básica em todas suas etapas e modalidades e, de modo inédito, previu valores diferenciados para o tempo integral” (MOLL, 2012, p. 27), e a criação do Programa Mais Educação pela Portaria Normativa Interministerial nº 17, de 24 de abril de 2007.

Dada a expansão do Programa Mais Educação nas escolas do meio urbano, e frente às pressões de diferentes movimentos sociais no campo, intensificou-se a necessidade de ampliação do Programa para as escolas do campo. Frente a isso, em 2009, foi produzido um documento contendo análises de um grupo de trabalho dedicado a refletir sobre as definições para oferta de educação integral para o campo. A proposta originária das orientações do grupo pressupunha uma educação "que afirme o campo como o lugar onde vivem sujeitos de direitos, 
com diferentes dinâmicas de trabalho, de cultura, de relações sociais, e não apenas como um espaço que meramente reproduz os valores do desenvolvimento urbano" (BRASIL, 2014, p. 21).

O grupo de trabalho buscava a construção de um referencial para a oferta de educação em tempo integral no campo, e foi composto por representantes de diferentes movimentos sociais e sindicais, de ministérios, algumas secretarias municipais de educação e institutos superiores de educação nas definições da nova política. A partir das definições tomadas no ano de 2009, segundo as estimativas do Ministério da Educação (MEC), os sistemas de educação se movimentaram no sentido de implantar o Programa Mais Educação nas escolas caracterizadas como campo, a partir de 2012, com a finalidade de estruturar a educação integral nesses locais.

A partir do ano de 2012 a política de educação em tempo integral passou a ser inserida nas escolas do campo, subsidiada pela regulamentação política cujo processo é constante em uma das ações do Programa Nacional de Educação do Campo (PRONACAMPO), instituído em 20 de março de 2012, “com a finalidade de atender às diretrizes propostas para a política de educação para o campo e assegurar apoio técnico e financeiro do Ministério da Educação, aos Estados, Distrito Federal e Municípios, nos termos do Decreto no 7.352 de 2010”. (BRASIL, 2014, p. 7).

A proposta que emerge da implantação do tempo integral nas escolas do campo visa qualificar os tempos e espaços de forma específica não mitigando os saberes e as vivências desses povos. Nesse sentido, empreende-se a ampliação de oportunidades educativas a partir do pressuposto da formação integral dos indivíduos, considerando, nesse processo, o modo de viver, pensar e produzir próprios da vida do campo. Isso implica na construção de um projeto de educação que amplie o território da escola através de parcerias com outros espaços de formação, no intento de ampliar as oportunidades de aprendizagem.

De acordo com a proposição da política para o campo, o processo educativo deve se desenvolver de modo mais significativo a partir da dinâmica do próprio campo, como base para a educação dos sujeitos. Muito se aproxima de "uma tentativa de criação de uma escola que trabalhe com métodos ativos, visando que o indivíduo construa seu conhecimento a partir de suas práticas e seus saberes" (BEZERRA, 2011, p. 116).

Desse modo, a política de educação em tempo integral pauta-se no domínio do enfrentamento das desigualdades sociais e educacionais, presente na história da educação do campo.

Os referencias para a política de educação em tempo integral, bem como o disposto no novo Plano Nacional de Educação, tomaram por base os princípios teórico - metodológicos 
que referenciam a educação do campo. Esses princípios foram legitimados pela conjunção de forças dos movimentos sociais e sindicais e, posteriormente, pelos marcos normativos que deram sustentação legal para a construção da política de uma educação específica para o campo, sendo destaque nesse contexto, a Resolução CNE/CEB 01, de 3 de abril de 2002, e o Decreto $\mathrm{n}^{\mathrm{o}} 7.352$, de 4 de novembro de 2010 .

\section{A IMPLEMENTAÇÃO DO PROGRAMA MAIS EDUCAÇÃO NAS ESCOLAS DO CAMPO NO MUNICÍPIO DE SANTARÉM}

\subsection{O município de Santarém}

O município de Santarém está situado no norte do Brasil, na região Oeste do Estado do Pará, à margem direita do Rio Tapajós. As principais vias de acesso ao município se dão pelo meio fluvial através do Rio Tapajós e Amazonas, o rodoviário por meio da Rodovia BR 163 (Cuiabá-Santarém) e BR-230 (Transamazônica) e por via aérea através de voos diários com destino as cidades de Belém e Manaus, se estendendo a partir destas cidades para outras regiões do país. Santarém é reconhecida como cidade polo da região Oeste do Pará pois oferece melhor infraestrutura econômica e social e o setor de serviços mais desenvolvido do interior do Estado do Pará.

Santarém é um município com uma rede educacional composta de várias instituições educacionais públicas e privadas. As instituições oferecem da educação infantil até o ensino superior. Em conformidade com informações do Plano Municipal de Educação, interstício 20152025, a rede educacional do município conta com 397 escolas públicas, "sendo 320 localizadas no espaço campestre - 231 escolas na região de rios e 90 na região de planalto, e 76 fixadas no limite urbano" (SANTARÉM, 2015, p. 22).

\subsection{A conexão das atividades pedagógicas entre turnos nas escolas do campo}

Quando tratamos da educação integral, focalizando a organização pedagógica, agregamos algumas extensões tais como: tempo ampliado, espaço, diferentes macrocampos, currículo e novas oportunidades educativas. Estes elementos devem ser ressignificados no terreno das escolas que implantaram o Programa Mais Educação; este, por sua vez, ao ser implementado no tempo 
ampliado é operacionalizado através da oferta de diversas atividades socioeducativas, atuando no sentido de preparar as escolas para a educação integral. Nesse sentido, o Projeto Político Pedagógico (PPP) se constitui como um elemento crucial para construção de uma estrutura que assegure a execução da educação integral, no âmbito da organização pedagógica. Defendemos a incorporação da proposta de educação integral na perspectiva de uma formação múltipla englobando os aspectos cognitivos, sociais, afetivos, emocionais, para os sujeitos, primeiramente no âmbito do PPP das escolas, para posterior implementação na prática pedagógica.

Tomando como parâmetro a organização pedagógica das escolas que executaram o Programa Mais Educação e focalizando, de início, a articulação dos conhecimentos das atividades constantes nos macrocampos do Programa Mais Educação, junto com os saberes escolares orientados pelo currículo formal - e os saberes das comunidades (saber local), compreendemos que as atividades pedagógicas do tempo escolar devem ser planejadas pelos professores junto com as atividades pedagógicas desenvolvidas pelos monitores, e contempladas no tempo ampliado.

O macrocampo orientação de estudos e leitura configura-se no sentido de dar continuidade às atividades pedagógicas desenvolvidas pelos professores do tempo escolar, em consonância com as desenvolvidas pelos monitores do programa. Foi no sentido de entender como as atividades pedagógicas foram planejadas, com a implementação do Programa Mais Educação, nas escolas do campo que questionamos professores do tempo escolar e monitores sobre o planejamento e organização das atividades pedagógicas. Dentre os doze sujeitos entrevistados, sete informaram que planejavam junto com os monitores a organização das atividades de sala de aula para serem desenvolvidas nos dois turnos e cinco informaram que não havia essa preocupação e planejamento.

Da análise das respostas dos sujeitos envolvidos na pesquisa, há o reconhecimento da importância de planejarem as atividades pedagógicas de modo que se estabeleça a conexão entre o proposto no tempo escolar com as atividades do tempo ampliado. No entanto, apesar de a maioria afirmar que existe o processo de planejamento das atividades na escola, notamos uma resistência bastante enfática na fala de alguns professores, que se sentem alheios em relação à proposta do Programa, o que nos chamou a atenção.

Não. Pra mim, geralmente nos meus conteúdos, não tinha nenhuma relação. Não batia o conteúdo com o nosso. Não tinha reunião... Vamos ver o que é pra gente fazer? Não tinha. (Professor MR 3) ${ }^{1}$

\footnotetext{
${ }^{1}$ Os nomes reais dos participantes foram mantidos em sigilo, na tentativa de garantir o anonimato das entrevistadas.
} Deste modo foram estipulados nomes fictícios aos sujeitos entrevistados. 
Um pouco distante... Não tinha assim muito planejamento e nem muito envolvimento também entre professor e o monitor. (Professor MU)

O estranhamento do grupo dos professores ao trabalho dos monitores é algo recorrente nas experiências de implementação do Programa Mais Educação. Titton e Pacheco (2015) fazem menção às tensões da educação integral no cotidiano das escolas; para os autores tal tensão se dá, dentre outros fatores, no nível do estranhamento dos professores à entrada de diferentes professores (monitores) na escola. A falta de experiência que os monitores mostraram na condução do programa nas escolas, reforçou a resistência dos professores, refletindo-se assim na desconfiança em relação ao trabalho desenvolvido no tempo ampliado.

Em observância à questão levantada pelos professores do tempo escolar, percebemos, da análise das entrevistas, que os monitores sentiram os seus próprios trabalhos comprometidos à frente do PME pela falta de uma preparação adequada. Quando questionados sobre isso foram evidenciadas falas como:

Eu não me sentia não, logo no começo não sabia nem como fazer, não tinha a mínima ideia, foi meu primeiro contato com sala de aula. Aí a professora já tinha dado e ela ajudava a gente, aí foi até que peguei a experiência, né? (Monitor MR 1)

Se tivesse como contribuir mais, né? Pelo pouco entendimento que a gente tinha, se tivesse assim um acompanhamento maior [...] a gente trabalhava com aquilo, mas não tinha assim aquela ideia profunda do que mais ou menos era, para que era, qual o objetivo. A gente trabalhava assim, se tivesse uma oficina a gente ensinava o aluno naquela oficina, só. (Monitor SI 1)

Ademais, destaca-se que esses monitores vêm construindo um papel "docente" sem qualificação adequada no interior do programa nas escolas do campo, atuando assim como leigos. Essa é uma realidade pungente, em especial, quando se trata de uma escola localizada no meio rural, uma vez que esta foi historicamente marcada pela atuação de professores com baixa qualificação. Aliada a isso, nota-se que a condição de voluntários exercida pelos monitores representa a secundarizarão do papel destes no espaço escolar.

Embora a orientação da política previsse a atuação de outro tipo de profissional que desse suporte ao trabalho dos monitores, como os coordenadores e educadores comunitários, em nível local, não foi percebida a atuação destes interlocutores. Tal situação foi justificada pela falta de recursos para realizar os referidos pagamentos o que impossibilitou a atuação destes no exercício da função. 
Apesar dos debates sobre a implementação da educação integral como jornada ampliada no Brasil ser colocada em pauta como estratégia de melhoria do ensino no âmbito das políticas educacionais, notamos, em face às realidades das escolas pesquisadas, que esse debate ainda necessita ser fortalecido no âmbito pedagógico e no terreno das escolas onde a política se torna realidade.

\subsection{A relação espaço-tempo na organização pedagógica das escolas do campo}

A ampliação do tempo de formação, aliado à ampliação do território educativo das escolas, para outros espaços, consubstanciam o ideal da educação integral. Leclerc e Moll (2012, p. 20) situam o tempo como "referência à ampliação da jornada escolar, e espaço, com referência aos territórios em que cada escola está situada e seus possíveis itinerários educativos".

As definições da política de educação em tempo integral não se dão ao acaso, assistimos que sua implantação se aporta em uma dimensão temporal disposta na consecução do Programa Mais Educação. Importante situar a reflexão que Francisca Lima, Lucinete Lima e Maria Cardozo (2013) constroem a respeito da vertente ampliação de tempo presente na estruturação da política de educação em tempo integral:

\footnotetext{
Nesse sentido, cabe problematizar essa visão limitada com que a educação integral se apresenta nas políticas estatais com apenas ênfase na ampliação da jornada escolar da educação básica e sua operacionalização por meio de atividades desconectadas de um projeto curricular ou formativo. Portanto, no Brasil, a educação integral ainda é um ideal a ser buscado no processo de materialização da melhoria da qualidade do ensino na realidade nacional, regional e local. (LIMA, F.; LIMA, L.; CARDOZO, 2013, p. 23).
}

Essa é uma observação pertinente, pois a pesquisa permitiu a visualização de uma organização pedagógica das escolas do campo distante da educação integral; esse distanciamento se deu inicialmente nos PPPs das escolas que não previam a inserção de uma proposta de formação inteira e, em sequência, na organização da relação espaço-tempo que foi operacionalizada com base na improvisação.

No que tange à organização do tempo, as cinco escolas pesquisadas, seguindo orientação da secretaria de educação do município, implementaram o Mais Educação no horário 
intermediário $^{2}$ pois, segundo a coordenação geral do programa, a distância das escolas do campo em relação às residências dos alunos dificultaria a frequência nas ações propostas. Deste modo, a opção mais viável seria a implementação do programa em um horário alternativo - o intermediário.

Constatamos a improvisação no que tange à organicidade das variáveis (espaço-tempo) no intento de compatibilizar as atividades do PME dentro das escolas. Santos (2011) evidencia a improvisação em outros estudos, sendo indicada como um elemento presente na organização pedagógica de outras propostas de implementação da educação em tempo integral no Brasil.

Podemos inferir que essas fragilidades foram fruto do modo como a politica foi implementada nas escolas do campo; isso implicou e refletiu na falta de planejamento, direcionamento e orientação no âmbito local das escolas, não sendo reservado o tempo necessário para organizar a implementação do PME.

A análise sobre as experiências das escolas do campo que implementaram o programa Mais Educação confirmam os descaminhos que a política de educação em tempo integral vem tomando na prática pedagógica, descaminhos baseados na improvisação da organização pedagógica dos elementos que estruturam o programa e a proposta de educação integral (relação espaço-tempo, articulação das atividades pedagógicas, tempo ampliado, PPP).

\subsection{Implicações da ampliação do tempo sobre o rendimento discente}

Decorrente de pesquisa realizada com a fundação Itaú, junto com grupo do Banco Mundial e MEC, foram publicados, em 2015, resultados condensados no Relatório de Avaliação Econômica e Estudos Qualitativos com o intuito de fazer um balanço dos impactos da implementação do PME nas escolas brasileiras, nos fatores rendimento escolar e evasão. Nessa avaliação, foram considerados os indicadores relativos a taxa de abandono, desempenho em português e desempenho em matemática.

No Brasil, essa avaliação apontou o inquestionável papel que o Programa desenvolveu, entre os anos de 2008 a 2011, como estratégia de indução da Educação Integral nas escolas públicas e vem se constituindo ao longo do tempo como referência para a educação integral

\footnotetext{
${ }^{2}$ Compreende o horário de atividades entre o intervalo dos turnos matutino e vespertino. Desse modo, o intermediário abarca o horário de 11:00h às 14:00h, coincidindo com o período de almoço e descanso de estudantes do turno matutino que participam do Programa Mais Educação.
} 
no país; no entanto, ainda carece de melhoramentos no âmbito do "seu desenho e na sua implementação" (FUNDAÇÃO ITAÚ SOCIAL, 2015, p. 6).

No que tange ao rendimento acadêmico e evasão tendo como parâmetros as disciplinas de Português e Matemática, o estudo do Banco Mundial e Fundação Banco Itaú indicou que na $1^{\text {a }}$ fase de implementação do PME até 2011, "não são encontrados resultados de melhoria no desempenho médio dos alunos na Prova Brasil, nem na taxa de abandono, quando comparamos escolas que tiveram o programa com outras sem ele, mas com características similares" (FUNDAÇÃO ITAÚ SOCIAL, 2015, p. 6).

Além disso, em termos de índices de rendimento dos alunos na disciplina de Matemática, em curto prazo de implementação do programa, no ano de 2008, o mesmo apresentou índices negativos de aproveitamento, em Matemática, e já em 2010 esses índices melhoraram. A leitura por trás desses dados indica que:

Desse modo, pode ser que, à medida que o programa se consolida, os impactos melhorem, e o efeito negativo sobre o aproveitamento dos alunos em Matemática se dissipem. Nesse sentido, o oferecimento de orientações mais assertivas às escolas, sobretudo na esfera pedagógica, juntamente com um monitoramento mais estruturado do programa, poderia aprimorar sua implementação e eficácia. (FUNDAÇÃO ITAÚ SOCIAL, 2015, p. 46)

Em contraposição à pesquisa realizada pelo Banco Mundial e Fundação Itaú, Jaqueline Moll - em discurso proferido em uma audiência no Senado, a qual reuniu especialistas em educação integral que discutiam a Avaliação da Política Pública Educação de Tempo Integral (Programa Mais Educação), em 2015 - questionou a metodologia utilizada pelo Banco Mundial e Fundação Itaú.

No que concerne às implicações da ampliação do tempo, sobre o rendimento dos alunos das escolas do campo pesquisadas, destaca-se: das análises das entrevistas que o fator rendimento dos alunos foi uma vertente em evidência, dos vinte e seis entrevistados pertencentes aos grupos de Diretores, Professores e Pais, vinte apontaram que os mesmos apresentaram um maior rendimento nas notas e desempenho na sala de aula após a implementação do PME, quatro entrevistados informaram que não sentiram esses reflexos e dois não responderam a questão. Os discursos a seguir confirmam como os sujeitos percebem a ampliação do tempo enfocando a melhoria no desempenho acadêmico dos estudantes.

É bom, foi muito bom mesmo, as notas melhoraram, melhorou muita coisa né, os meus filhos melhoraram. (Pai P 1) 
Eu acredito que sim, contribuiu na questão de aprendizagem dos alunos, principalmente na parte de conhecimento aonde é trabalhada a leitura e a matemática. Eu comprei com o dinheiro que veio para o programa material pedagógico, os monitores trabalhavam com jogos e com o tempo as crianças foram melhorando seu desempenho escolar. (Diretora MU)

A esse respeito, damos destaque às informações colhidas em uma escola localizada na região de rios, com base em informações coletadas na secretaria da escola. $O$ índice de rendimento final de aprovação dos alunos contou com um aumento no ano de 2015, ano em que o PME foi implementado; este índice foi baseado em um levantamento estatístico que a escola realiza ao final de cada ano. Desse modo, entre os anos de 2013 a 2015, foi indicado que o índice de $91,2 \%$ de aprovação no ano de 2013 , saltou para 95,5\% no ano de 2015 . Concernente ao Índice de Desenvolvimento da Educação Básica (Ideb) no $4^{\circ}$ e $5^{\circ}$ ano na instituição pesquisada, a escola ultrapassou a meta projetada para 2015 , de 3,6 para 3,8.

Em observância ao Ideb de outra escola do campo pesquisada, não tivemos acesso às estatísticas de aprovação dos alunos ao final do ano, mas notamos que no ano de implementação do programa, em 2013, o Ideb da escola estava em 4,1, e em 2015, com a extinção do programa na escola o índice caiu para 3,8.

Por certo, reconhecemos que o aumento do índice de desempenho das escolas resultou da soma de vários esforços, e de outros programas, todavia, não há como negar que a implementação do Programa Mais Educação exerceu influência positiva no processo de melhoria do rendimento escolar discente.

A pesquisa realizada por Souza, Rosário e Lima (2016, p. 155) aponta que o aumento no resultado do Ideb no Estado do Pará deve-se, entre outros fatores à:

elevação do número de crianças matriculadas em escolas de tempo integral da zona urbana e rural, [...] como podemos constatar, o ensino fundamental no estado do Pará, segundo o Ideb, vem crescendo de maneira contínua, depois da criação do programa (Mais Educação), superando a meta projetada. (SOUZA; ROSÁRIO; LIMA, 2016, p. 155, grifo do autor)

É importante situar que a ampliação do tempo não deve se limitar a melhorar os resultados das escolas, mas a ampliar simultaneamente as condições e oportunidades de aprendizagens; nesse sentido Cavaliere (2007, p. 1017) acrescenta que "torna-se então necessário abordar a questão do tempo de escola de forma a ir além da tentativa de resolver os déficits da escola pública brasileira, nos moldes em que hoje ela se estrutura". 
Afinado ao estudo do rendimento escolar, a questão do reforço escolar e retirada dos alunos da rua foi evidenciada nas entrevistas realizadas nas escolas do campo. Cavaliere (2014, p. 1213) afirma que "o que vem sendo chamado de educação integral é um grande conjunto de atividades de diferentes naturezas, às quais se junta o reforço escolar”. Embora o programa preveja novas atividades educacionais no intento de reduzir a evasão, a repetência e a distorção de idade-série, por meio de ações culturais, educativas, esportivas, de educação ambiental, de educação em direitos humanos e de lazer, não deve se limitar a ser uma "dose" de reforço para melhoria do rendimento; pensamos que, além de tudo isso, o programa deve constituir-se por espaços e tempos que propiciem condições de crescimento, não só no nível cognitivo, mas afetivo, emocional, entre outros.

\section{CONSIDERAÇÕES FINAIS}

A reflexão que nos é possibilitada fazer, após a análise da implementação da política de educação em tempo integral nas escolas do campo, indica que a forma como a política vem sendo implementada no terreno das escolas tem se distanciado da educação integral; talvez, as inúmeras problemáticas estruturais que as escolas apresentam diante da implementação da política, como falta de estrutura física, qualificação para monitores e professores, falta de esclarecimentos conceituais e pedagógicos dos sujeitos sobre a educação integral, engessem as condições para criar possibilidades de um programa que tenha a educação integral como horizonte a ser de fato praticado.

O sentido de se integrar a experiência educativa do Programa Mais Educação nas escolas do campo aponta para inúmeros desafios de se desenvolver a educação integral. Os desafios foram postos, inicialmente, no nível da implantação da política nas escolas, então realizada de forma aligeirada, com fins de cumprimento dos prazos de adesão estipulados pelo MEC.

De certo, tal interveniência implicou no comprometimento da implementação do programa nas escolas, isso ficou evidente no limitado esclarecimento dos sujeitos a respeito da proposta do programa. Por considerar os monitores como os principais interlocutores do programa nas escolas, percebemos que estes eram o grupo mais alheio à proposta de educação integral, dando-se destaque a falta de qualificação e preparação para estarem à frente do PME. Apontamos que há a secundarização do trabalho dos monitores, que é caracterizado como um trabalho de natureza voluntário. 
No que se refere à organização pedagógica das escolas pesquisadas pontuamos a falta de articulação entre as atividades do tempo escolar em relação ao tempo ampliado, a ausência de articulação é tencionada por fatores externos ao ambiente escolar, como estranhamento à entrada de professores nas escolas que não são de fato professores - podemos até mesmo introduzir a ideia de um novo professor leigo atuando no programa - além disso, indicamos a desconfiança dos professores em relação ao teor formativo das atividades desenvolvidas pelos monitores, pois o ambiente escolar continua arraigado às práticas que consideram somente formativas aquelas atividades desenvolvidas dentro da sala de aula.

De fato, não podemos negar que o horizonte formativo das atividades desenvolvidas no interior do programa está distante da educação integral, se impondo como mais um desafio, pois o improviso na articulação dos elementos constitutivos do programa, na perspectiva da educação integral (relação espaço-tempo) tem se constituído como parâmetro e referência para compatibilizar as demandas do programa dentro das escolas.

O improviso deixaria de ser marca da implementação da educação integral se sua articulação ao PPP e uma ampla redefiniçao curricular fosse uma condição essencial da orientação e implementação da política; no entanto, o caráter emergencial de implantação de políticas educacionais no terreno da prática pedagógica vem escamoteando a busca de solução para seus reais fins.

Embora os desafios da implementação do programa demonstrem limites e fragilidades, indicamos alguns avanços relacionados ao interesse dos estudantes e melhoria nos resultados escolares dos alunos que apresentam dificuldades. Notadamente como o programa foi implementado com a perspectiva de aula de reforço, especialmente no macrocampo "campos do conhecimento" que preconizava o reforço de habilidades da leitura, da escrita e da Matemática, os resultados tenderam a melhorar.

Tempo e espaço são elementos que necessitam ser ressignificados, o tempo no sentido de tornar o tempo ampliado tão formativo quanto o tempo escolar, pois entendemos que ambos devem perfazer uma unidade. Em relação ao espaço, apontamos falta de clareza dos sujeitos em entender que os espaços externos à escola perfazem espaços de formação, pois em sua maioria o uso dos espaços limitava-se às salas de aula.

Os desafios da implementação do programa demonstram limites e fragilidades, indicam alguns avanços relacionados ao interesse dos alunos e melhoria nos resultados escolares dos alunos que apresentam dificuldades. Notadamente, como o programa foi implementado com a perspectiva de aula de reforço, especialmente no macrocampo campos do conhecimento que 
preconizava o reforço de habilidades da leitura, escrita e na Matemática, os resultados tenderam a melhorar.

Desse modo, embora o programa indique avanços em termos de melhoria do rendimento dos alunos, no que tange à efetivação da educação integral, ainda apresenta fragilidades que merecem ser reavaliadas pela política de educação em tempo integral, o que perpassa pelo aumento de investimentos para melhoria da infraestrutura das escolas, qualificação de todos os envolvidos diretamente com o processo.

\section{Referências}

BARDIN, L. Análise de conteúdo. Trad. Luís Antero Reto e Augusto Pinheiro. São Paulo: Edições 70, 2011.

BEZERRA NETO, L.; BEZERRA, M. C. S. (Org.). Educação para o campo em discussão: reflexões sobre o programa Escola Ativa. São José: Premier, 2011.

BRASIL. Lei no 9.394, de 20 de dezembro de 1996. Estabelece as diretrizes e bases da educação nacional. Diário Oficial da União, Poder Legislativo, Brasília, DF, 23 dez. 1996. Seção 1, p. 27833.

. Lei $\mathbf{n}^{\mathbf{0}}$ 10.172, de 9 de janeiro de 2001. Aprova o Plano Nacional de Educação e dá outras providências. Diário Oficial da União, Poder Legislativo, Brasília, DF, 10 jan. 2001. Seção 1, p. 1.

. Resolução CNE/CEB n ${ }^{\circ}$ 1, de 3 de abril de 2002. Institui as Diretrizes Operacionais para a Educação Básica nas Escolas do Campo. Diário Oficial da União, Brasília, DF, 9 abr. 2002. Seção 1, p. 32.

. Lei no 11.494, de 20 de junho de 2007. Regulamenta o Fundo de Manutenção e Desenvolvimento da Educação Básica e de Valorização dos Profissionais da Educação FUNDEB, de que trata o art. 60 do Ato das Disposições Constitucionais Transitórias; altera a Lei ${ }^{\circ} 10.195$, de 14 de fevereiro de 2001; revoga dispositivos das Leis ${ }^{\text {os }} 9.424$, de 24 de dezembro de 1996, 10.880, de 9 de junho de 2004, e 10.845, de 5 de março de 2004; e dá outras providências. Diário Oficial da União, Poder Executivo, Brasília, DF, 21 jun. 2007. Seção 1, p. 7.

. Decreto $n^{0} 7.083$, de 24 de janeiro de 2010. Dispõe sobre o Programa Mais Educação.

Diário Oficial da União, Poder Executivo, Brasília, DF, 27 jan. 2010. Edição Extra, p. 2. . Ministério da Educação. Secretaria de Educação Básica. Educação no Campo. Brasília, DF: Secretaria de Educação Básica, 2014. 48 p. (Série Cadernos Pedagógicos Mais Educação).

- Ministério da Educação. Secretaria de Educação Básica. Diretoria de Currículos e Educação Integral. Manual Operacional de Educação Integral. Brasília, 2014. 
CARVALHO, V. B. As influências do pensamento de John Dewey no cenário educacional brasileiro. Revista Redescrições, [s.1.], v. 3, n. 1, p. 58-77, 2011. Disponível em: <https://goo. gl/6f7odb>. Acesso em: 13 ago. 2016.

CAVALIERE, A. M. Tempo de escola e qualidade na educação pública. Educação \& Sociedade, Campinas, v. 28, n. 100, p. 1015-1035, 2007. Disponível em: $<$ https://goo.gl/SsWSwa $>$. Acesso em: 27 fev. 2018. 2010 .

. Anísio Teixeira e a educação integral. Paidéia, Rio de Janeiro, v. 20, n. 46, p. 249-259,

. Escola pública de tempo integral no Brasil: filantropia ou política de Estado? Educação \& Sociedade, Campinas, v. 35, n. 129, p. 1205-1222, 2014. Disponível em: < https://goo. g1/2jVS1o>. Acesso em: 1 ago. 2014.

CUNHA, M. V. John Dewey, a outra face da escola nova no Brasil. In: GHIRALDELLI JR., P. (Org.). O que é filosofia da Educação? 3. ed. Rio de Janeiro: DP\&A editora, 2002. p. 248-263.

FUNDAÇÃO ITAÚ SOCIAL. Relatório de avaliação econômica e estudos qualitativos: o programa Mais Educação: Ministério da Educação. São Paulo: Fundação Itaú Social, 2015. 120 p. (Série Avaliação econômica de projetos sociais).

LECLERC, G. F. E.; MOLL, J. Educação integral em jornada diária ampliada: universalidade e obrigatoriedade? Em Aberto, Brasília, DF, v. 25, n. 88, p. 17-49, 2012.

LIMA, F. C. S; LIMA, L. M.; CARDOZO, M. J. P. B. Educação integral: ideário pedagógico, políticas e práticas. São Luís: Edufma, 2013.

MOLL, J. A agenda da educação integral: compromissos para sua consolidação como política pública. In: MOLL, J. (Org.). Caminhos da educação integral no Brasil: direitos a outros tempos e espaços educativos. Porto Alegre: Penso, 2012.

SANTARÉM. Secretaria Municipal de Educação. Plano municipal de educação 20I5-2025. Santarém: SEMED, 2015.

SANTOS, K. S. Políticas públicas educacionais no Brasil: tecendo fios. In: SIMPÓSIO BRASILEIRO DE POLÍTICA E ADMINISTRAÇÃO DA EDUCAÇÃO, 25., 2011, São Paulo. Anais... São Paulo: Anpae, 2011. Disponível em: <https://goo.gl/1RKskV $\geq$. Acesso em: 27 fev. 2018.

SOUZA, M. F. M.; ROSÁRIO, M. J. A.; LIMA, M. C. O cenário da educação do campo no estado do Pará e a política nacional de educação em tempo integral: uma realidade complexa. In: COLARES, M. L. I. S.; COSTA, S. A. (Orgs.). Educação integral: concepções e práticas a luz dos condicionantes singulares e universais. Curitiba: CRV, 2016. p. 139-162.

TITTON, M. B. P.; PACHECO, S. M. Diálogos possíveis à construção de projeto político e pedagógico na perspectiva contemporânea da educação integral. Educação em Revista, Belo Horizonte, v. 31, n. 4, p. 135-153, 2015. Disponível em: <https:/goo.gl/HqV4TC >. Acesso em: 13 set. 2016. 
Vasconcelos, C. R. A.; Rocha, S. H. X

Recebido em: 29/10/2016

Revisado em: 06/12/2017

Aprovado para publicação em: 15/12/2017

Publicado em: 20/12/2017 